ejournal Keperawatan (e-Kp) Volume 7 Nomor 1, Februari 2019

\title{
HUBUNGAN DISMENORE DENGAN GANGGUAN SIKLUS HAID PADA REMAJA DI SMA N 1 MANADO
}

\author{
Indah Juliana \\ Sefti Rompas \\ Franly Onibala \\ Program Studi Ilmu Keperawatan Fakultas Kedokteran \\ Universitas Sam Ratulangi \\ Email : ijuindah@gmail.com
}

\begin{abstract}
Teenagers is the transition period, which characterized by the changes of either physical, psychie, and biological which we call it as puberty. Puberty in teenage girl marked by menstruation, the first year of first menstruation or menarche is time where often disruption happened. The Purpose of this research is to know the relationship between the dysmeorrhea with the disturbance of menstrual cycle of the teenage girls in SMA N 1 Manado. This research methodology is using the observational design with the Cross Sectional approach. The population of this research were 1.103 female students, and the determination technique is using Slovin formula. The research sample were 92 people who met the inclusion criteria. The research instrument are using observation sheet regarding the intensity of pain and menstrual cycle experienced by the respondents. The result of statistical test using the Chi Square with the confidence level of 95\% $(\alpha=0.05)$ with the value $p=0.023$, which means $p<\alpha=0.05$. The conclusion is, the result of this research showing a significant relation between dysmenorrheal and menstrual cycle disorders in teenage girls in SMA N 1 Manado.
\end{abstract}

Keywords : Dysmenorrhea, Mesntrual Cycle, Teenager.

Abstrak: Remaja merupakan masa transisi, yang ditandai dengan perubahan baik fisik,
psikis, maupun biologis yang kerap disebut pubertas. Pubertas pada remaja putri ditandai
dengan menstruasi, tahun-tahun pertama sejak menstruasi pertama kali atau menarche
merupakan masa-masa sering terjadinya gangguan. Tujuan penelitian ini untuk mengetahui
hubungan antara dismenore dengan gangguan siklus haid pada remaja di SMA N 1 Manado.
Penelitian ini merupakan Metode penelitian kuantitatif dengan desain penelitian yaitu cross
sectional. Populasi pada penelitian ini sebanyak 1.103 siswa perempuan, teknik penentuan
sample menggunakan rumus slovin, didapati sampel sebanyak 92 orang yang memenuhi
kriteria inklusi. Instrument penelitian ini menggunakan lembar observasi mengenai intenitas
nyeri dan siklus haid yang dialami responden. Hasil uji statistic menggunakan uji Chi Square
dengan tingkat kepercayaan $95 \%$ ( $\alpha \leq 0.05$ ), di dapati nilai $p=0.023$, yang berarti $<<=0.05$.
Kesimpulan hasil penelitian ini menunjukan adanya, hubungan yang signifikan antara
dismenore dengan gangguan siklus haid pada remaja di SMA N 1 Manado. Kata Kunci : Dismenore, Siklus Haid, Remaja. 


\section{PENDAHULUAN}

Remaja merupakan masa transisi dari anak-anak menjadi dewasa, menurut World Health Organization (WHO) remaja adalah rentang usia 10-19 tahun. Pada masa remaja terjadi perubahan hormonal, fisik, psikologis maupun sosial. Dimana kondisi tersebut dimaknai dengan kondisi pubertas. Salah satu tanda pubertas pada remaja putri yaitu terjadinya menstruasi (Batubara, 2010).

Menstruasi pertama ialah menarche, pada permulaan usia menarche biasanya rentan terhadap masalaha atau gangguan menstruasi. Dalam 100 tahun terakhir ini usia menarche telah bergeser ke usia yang lebih muda, dikarenakan meningkatnya kesehatan umum dan gizi (Fitriningtyas dkk, 2017). Rata-rata sekarang usia menarche berkisar antara 1113 tahun, sebuah penelitian yang dilakukan oleh Pratiwi (2017) pada remaja di SMA N 1 Makasar, hasil penelitian menunjukan dari 90 responden yang diteliti mayoritas responden menstruasi pertama (menarche) di usia 12 tahun, yaitu sebanyak 38 orang (42.2\%). Keluhan menstruasi sering dialami oleh remaja pada tahun tahun awal usia menarche, terkait dengan nyeri haid dan siklus menstruasi yang dialami.

Siklus menstruasi merupakan waktu sejak hari pertama menstruasi sampai datangnya menstruasi periode berikutnya. Gangguan siklus haid merupakan masalah yang terjadi pada pola siklus menstruasi wanita yang meliputi polimenore $(<20$ hari), oligomenore $(>35$ hari), dan amenore ( $>3$ bulan) (Sitoayu dkk, 2016).

Penelitian yang dilakukanpada remaja putri Turki ditemukan 31,2\% mengalami ketidakteraturan pola menstruasi (Felicia, 2015). Penelitian lain yang dilakukan pada remaja di India melaporkan sebanyak $22,1 \%$ remaja mengalami ketidakteraturan pola menstruasi (Larasa T, Alatas F, 2016).Di Indonesia penelitian yang dilakukan oleh Mesarini BA \& Astuti VW ( 2013) pada mahasiswa tingkat IV di STIKES Rumah Sakit Baptis didapati bahwa 57,1\% mahasiswi mengalami gangguan siklus haid.

Gangguan siklus haid merupakan masalah yang kerap dikeluhkan oleh remaja, selain itu keluhan lain yang dikeluhkan remaja juga ialah dismenore atau nyeri haid. Nyeri haid atau dismenore merupakan keluhan ginekologisakibat ketidakseimbangan hormon progesteron sehingga mengakibatkan timbulnya rasa nyeri yang dialami wanita

Angka kejadian dismenore di dunia sangat besar, rata-rata lebih dari 50\% perempuan di setiap Negara mengalami nyeri menstruasi. Di Amerika angka presentasenya sekitar $60 \%$ dan di Swedia sekitar 72\% sementara di Indonesia angkanya di perkirakan $55 \%$ perempuan usia produktif yang tersiksa oleh nyeri menstruasi (Gustina, 2015). penelitian yang di lakukan oleh Putri SA (2017) jumlah kejadian dismenore pada siswi kelas XI SMA N 52 Jakarta sebesar $86 \%$.

Pengambilan data awal yang di lakukan di SMA N 1 Manado, diketahui jumlah siswa sebanyak 2.033 siswa yang terdiri dari 930 siswa laki-laki dan 10.103 siswa perempuan. Telah dilakukan wawancara awal terhadap 10 orang siswa putrid, didapati 8 diantaranya mengalami dismenore dan 4 orang yang disertai dengan gangguan siklus haid yang tidak teratur yaitu 2 orang dengan polimenore ( $<21$ hari/ lebih dari sekali dalam sebulan), dan 2 orang lainnya dengan Oligomnore (>35 hari/ menstruasi lebih dari 2 bulan sekali), serta 2 orang lainnya tidak mengalami dismenore maupun gangguan siklus haid.

Berdasarkan fenomena yang ada peneliti tertarik untuk melakukan penelitian yang bertujuan untuk mengetahui "hubungan dismenore dengan gangguan siklus haid pada remaja di SMA N 1 Manado. 


\section{METODE PENELITIAN}

Penelitian ini merupakan penelitian kuantitatif dengan melakukan pendekatan cross sectional. Penelitian ini dilakukan di SMA N 1 Manado pada tanggal 21-23 November 2018 dengan spopulasi sebanyak 1.103 orang, dengan teknik stratified random sampling. Penetuan jumlah sampel menggunakan rumus slovin, didapati sampel pada penelitian ini sebesar 92 orang yang memenuhi criteria inklusi, dengan menggunakan instrument lembar observasi yang terdiri dari tingkat skala nyeri haid responden, dengan menggunakan numeric pain scale 0-10 dimana $0=$ tidak nyeri, $1-3=$ nyeri ringan, $4-6=$ nyeri sedang, $7-9=$ nyeri berat dan $10=$ nyeri tidak terkontrol. Sedangkan untuk siklus haid, terdapat pertanyaan mengenai siklus haid yang dialami oleh respon antara lain normal yaitu 21-35 hari, polimenore $<21$ hari, oligomenore $>35$ hari dan amenore $>3$ bulan.

Pengolahan data diakukan dengan cara yang pertama yaitu tahap mengkode data, yaitu mengklasifikasikan data dan jawaban menurut kategori masing-masing, kedua yaitu menyunting data, memeriksa kembali kelengkapan lembar observasi, kelengkapan data sesuai dengan jumlah responden, ketiga memasukan data, yaitu memasukan data kedalam computer untuk dianalisis menggunakan software, yang terakhir yaitu membersihkan data yaitu mengecek kembali kelengkapan data dalam software dan melakukan koreksi saat terjadi kesalahan.

Analisis data pada penelitian ini yaitu analisa univariat meliputi karakteristik responden, gambaran dismenore, dan gambaran siklus haid. Analisa bivariat yaitu untuk mengetahui hubungan dua variabel yang diduga memiliki korelasi. Digunakan uji Chi Square dengan tingkat kepercayaan 95\% $(\alpha=0.05)$.

\section{HASIL dan PEMBAHASAN}

\section{Karakteristik Responden}

Tabel 1. Distribusi dan presentase karakteristik umu responden di SMA N 1 Manado.

\begin{tabular}{ccc}
\hline $\begin{array}{c}\text { Karakteristik } \\
\text { Umur }\end{array}$ & n & $\mathbf{( \% )}$ \\
\hline 14 tahun & 6 & 6.5 \\
15 tahun & 31 & 33.7 \\
16 tahun & 30 & 32.6 \\
17 tahun & 25 & 27.6 \\
\hline Total & $\mathbf{9 2}$ & $\mathbf{1 0 0}$ \\
\hline
\end{tabular}

Sumber : Data Primer, 2018

\section{Analisa Univariat}

Tabel 2. Distribusi responden berdasarkan kejadian dismenore pada remaja di SMA N 1 Manado

\begin{tabular}{ccc}
\hline $\begin{array}{c}\text { Intensitas Nyeri Haid } \\
\text { (Dismenore) }\end{array}$ & $\mathbf{n}$ & $\mathbf{( \% )}$ \\
\hline Tidak Nyeri (0) & 18 & 19.6 \\
Nyeri Ringan (1-3) & 26 & 28.3 \\
Nyeri Sedang (4-6) & 29 & 31.5 \\
Nyeri Berat (7-9) & 19 & 20.7 \\
Nyeri Tidak Terkontrol (10) & 0 & 0 \\
\hline Total & $\mathbf{9 2}$ & $\mathbf{1 0 0}$ \\
\hline
\end{tabular}

Sumber : Data Primer, 2018

Tabel 3. Distribusi responden berdasarkan siklus haid pada remaja di SMA N 1 Manado

\begin{tabular}{ccc}
\hline Siklus Haid & $\mathbf{n}$ & $\mathbf{( \% )}$ \\
\hline 21-35 hari (Normal) & 35 & 38.0 \\
$<21$ hari (Polimenore) & 30 & 32.6 \\
$>35$ hari (Oligomenore) & 27 & 29.3 \\
>3 bulan (Amenore) & 0 & 0 \\
\hline Total & $\mathbf{9 2}$ & $\mathbf{1 0 0}$ \\
\hline
\end{tabular}

Sumber : Data Primer, 2018 


\section{Analisa Bivariat}

Tabel 4. Hubungan Dismenore dengan gangguan siklus haid pada remaja di SMA N 11 Manado

\begin{tabular}{|c|c|c|c|c|c|c|c|c|c|}
\hline \multirow{3}{*}{$\begin{array}{l}\text { Skala Nyeri } \\
\text { (Dismenore) }\end{array}$} & \multicolumn{8}{|c|}{ Siklus Haid } & \multirow{3}{*}{$\begin{array}{c}\mathrm{P} \\
\text { Value }\end{array}$} \\
\hline & \multicolumn{2}{|c|}{ Normal } & \multicolumn{2}{|c|}{ Polimenore } & \multicolumn{2}{|c|}{ Oligomenore } & \multicolumn{2}{|c|}{ Total } & \\
\hline & $\mathrm{n}$ & $\%$ & $\mathrm{n}$ & $\%$ & $\mathrm{n}$ & $\%$ & $\mathrm{n}$ & $\%$ & \\
\hline Tidak Nyeri & 12 & 66,7 & 5 & 27,8 & 1 & 5,6 & 18 & 100 & \\
\hline $\begin{array}{l}\text { Nyeri } \\
\text { Ringan }\end{array}$ & 8 & 30,8 & 11 & 42,3 & 7 & 26,9 & 26 & 100 & \\
\hline $\begin{array}{l}\text { Nyeri } \\
\text { Sedang }\end{array}$ & 9 & 31,0 & 11 & 37,9 & 9 & 31,0 & 29 & 100 & 0.023 \\
\hline Nyeri Berat & 6 & 31,6 & 3 & 15,8 & 10 & 52,6 & 19 & 100 & \\
\hline Total & 35 & 38,0 & 30 & 32,6 & 27 & 29,3 & 92 & 100 & \\
\hline
\end{tabular}

Sumber : Data Primer, 2018

\section{Karakteristik Responden}

Berdasarkan hasil penelitian karakteristik responden pada penelitian ini adalah siswi SMA N 1 Manado yang berjumlah 92 orang dengan jumlah terbanyak usia responden adalah 15 tahun yaitu 31 orang (33.7), diikuti dengan responden yang berusia 16 tahun 30 orang $(32.6 \%), 17$ tahun 25 orang $(27.2 \%)$, dan 14 tahun sebanyak 6 orang $(6.5 \%)$. Usia tersebut termasuk dalam kategori remaja dimana sesuai dengan WHO bahwa usia rentang remaja adalah 10-19 tahun. Usia remaja adalah masa dimana terjadi perubahan-perubahan baik secara psikis, maupun biologis. Salah satu masa terjadinya perubahan pada remaja kerab disebut dengan masa pubertas.

Salah satu tanda pubertas pada remaja putri ialah menstruasi. Menstruasi merupakan tanda dimana organ reproduksi pada wanita telah matang, terjadinya menstruasi pertama kali disebut juga menarche. Pada masa ini kerap ditemui masalah menstruasi antara lain yaitu dismenore atau nyeri haid dan juga gangguan siklus haid pada remaja, mengingat dimana masa remaja merupakan masa tahun-tahun awal menstruasi, dan sesuai dengan data responden yang menunjukan usia responden termasuk dalam kategori remaja yang merupakan masa tahun-tahun awal menarche yaitu 14-17 tahun.

\section{Dismenore}

Hasil penelitian variabel Dismenore (nyeri haid) yang diukur dengan skala numeric atau Numeric Rating Scale pada remaja di SMA N 1 Manadodidapati bahwa dari 92 responden yang termasuk dalam kriteria inklusi sebagian besar mengalami dismenore yaitu 74 orang $(80.5 \%)$, sedangkan 18 lainnya tidak mengalami dismenore (19.4\%), dan dari data yang diperoleh menunjukan bahwa responden yang mengalami nyeri ringan sebanyak 26 orang (28.3\%), nyeri sedang 29 orang $(31.5 \%)$, sedangkan nyeri berat 19 orang $(20.7 \%)$.

Berdasarkan penelitian ini diketahui bahwa mayoritas responden di SMA N 1 Manado mengalami dismenore, sejalan dengan penelitian yang dilakukan oleh Putri SA (2017) pada siswi kelas XI SMA N 52 Jakarta didapati sebanyak 101 siswi mengalami dismenore dengan presentase $86 \%$ dari total populasi sebanyak 117 responden.

\section{Siklus Haid}

a. siklus haid normal

Hasil penelitian menunjukan bahwa dari 92 responden, yang mengalami siklus haid normal sebanyak 35 orang dengan presentase $38.0 \%$. yaitu sebanyak 35 responden memiliki siklus haid berkisar antara 21-35 hari. Angka ini termasuk kategori minoritas mengingat dari jumlah keseluruhan responden, hanya 35 orang yang mengalami siklus haid normal, hal ini menunjukan bahwa mayoritas responden yang diteliti mengalami gangguan siklus haid yaitu sebanyak 57 orang $(62.0 \%)$ yang terbagi baik siklus haid polimenore,maupun oligomenore

b. polismenore

Hasil penelitian pada 92 responden di SMA N 1 Manado menunjukan sebanyak 30 orang (32.6\%) mengalami polimenore, hasil penelitian ini menunjukan perbedaan dengan penelitian yang di lakukan pada Remaja Putri di 
SMK YPKK 1 Sleman tahun 2017 dimana dari 70 responden yang diteliti hanya 9 orang yang mengalami gangguan siklus menstruasi polimenore dengan presentase sebesar 12.9\% (Sahmin, 2017). Perbedaan pola siklus menstruasi pada setiap individu berbeda, karena polimenore bisa disebabkan oleh ketidakseimbangan hormone, dan hal tersebut dapat mempengaruhi proses ovulasi

c. oligomenore

Dari hasil penelitian mengenai pola siklus haid pada remaja di SMA N 1 Manado hasil yang ditemui ialah dari 92 responden, yang mengalami siklus haid oligomenore sebanyak 27 orang dengan prevalensi $20.3 \%$ angka ini sedikit lebih kecil dari siklus polimenore yang dialami oleh responden. Oligomenore sendiri ialah gangguan siklus menstruasi dimana rentang jarak dari terakhir menstruasi sampai menstruasi periode berikutnya panjang yaitu melebihi angka normal dimana lebih dari 35 hari. Hasil Penelitian ini berbeda dengan hasil penelitian yang dilakukan oleh Sahmin (2017) pada Siswi SMK YPKK 1 Sleman dimana data 70 responden menunjukan angka keluhan oligomenore lebih tinggi dibanding dengan polimenore yaitu sebanyak 14 orang $(20.0 \%)$, sedangkan untuk polimenore hanya 9 orang $(12.9 \%)$ dan amenore 10 orang (14.3\%), sedangkan sisanya memiliki siklus haid normal.

d. amanore

Berdasarkan hasil penelitian di SMA N 1 Manado, tidak terdapat keluhan amenore dari 92 responden yang diteliti. Amenore merupakan masalah siklus menstruasi dimana seorang wanita yang sudah tidak mengalami menstruasi lebih dari 3 bulan. Banyak faktor yang dapat menjadi etiologi terjadinya amenore pada perempuan. Baik kehamila, maupun masalah pada organ reproduksi.

\section{Hubungan Dismenore dengan Gangguan Siklus Haid pada Remaja di SMA N 1 Manado}

Hubungan dismenore dengan gangguan siklus haid di analisa dengan menggunakan Uji Chi-Square, dari hasil uji statistic didapati nilai p-Value $=0.023$ $(\mathrm{p}<\alpha=0.05)$. Hal ini menunjukan bahwa adanya hubungan antara dismenore dengan gangguan siklus haid pada remaja di SMA N 1 Manado. Belum terdapat penelitian yang sama dengan variabel pada penelitian ini yaitu mengenai hubungan antara dismenore dengan gangguan siklus haid, kebanyakan penelitian yang ada ialah membahasa mengenai hubungan status gizi dengan kejadian dismenore, atau pun stress dengan gangguan siklus menstruasi.

Hasil penelitian menunjukan terdapat responden yang mengalami dismenore dengan skala nyeri berat namun memiliki siklus haid yang normal, yaitu sebanyak 6 orang. Hal ini dapat dipengaruhi oleh berbagai faktor seperti aktifitas fisik, status gizi, dan stress. Sebuah penelitian yang dilakukan di beberapa SMA di Kabupaten Rokaan Hulu mengenai faktor-faktor yang berhubungan dengan nyeri menstruasi (dismenore) pada remaja, didapati faktor olahraga teratur, dan riwayat keluarga memiliki hubungan yang signifikan dengan dismenore yang dialami oleh remaja (Handayani, 2014).

Data yang diperoleh dalam gangguan siklus haid polimenore, responden yang mengalami dismenore sekaligus polimenore yaitu 25 orang yang terbagi atas 11 orang dengan nyeri ringan, 11 orang nyeri sedang, dan 3 orang lainnya nyeri berat. Tingginya keluhan polimenore pada responden dengan dismenore sesuai dengan terori yang mengatakan faktor penyebab polimenore yaitu salah satunya adalah waktu dimana 3-5 tahun pertama setelah haid pertama merupakan masamasa rentan untuk terkena gangguan menstruasi atau polimenore (Sinagadkk, 2017) sesuai dengan usia responden yaitu termasuk dalam kategori remaja yang merupakan usia tahun-tahun pertama 
perkembangan organ reproduksi pada remaja putri.

Hasil dari data yang ada di tabel 4 . responden yang mengalami dismenore dengan intensitas skala nyeri berat sebagian besar mengalami siklus haid lebih dari 35 hari atau oligomenore, belum ada penelitian terkait hubungan antara intensitas nyeri haid dengan kejadian oligomenore pada remaja. Oligomenore merupakan suatu gangguan menstruasi yang kerab disebabkan oleh salah satunya ketidak seimbangan hormon, banyak faktor yang mungkin dapat mempengaruhi seperti gaya hidup, aktifitas, bahkan mungkin riwayat keluarga. Sebuah penelitian mengenai faktor-faktor yang memengaruhi siklus haid pada mahasiswa Fakultas Kedokteran Mulawarman didapati dari 194 responden 68 diantaranya mengalami siklus haid yang tidak normal, dengan keluhan terbanyak yaitu oligomenore sebanyak 47 orang, dari hasil penelitian diketahui faktor usia $<19$ tahun, usia menarke late, indeks masa tubuh lebih, aktifitas fisik berat, dan stress berat berpengaruh terhadap siklus menstruasi (Milanti dkk, 2017).

Mesntruasi pertama atau menarche merupakan masa dimana tanda bahwa telah matangnya organ reproduksi wanita, hal ini dapat memberikan dampak pada remaja, berdasarkan teori yang mengatakan bahwa tahun tahun awal menarche menjadi masa yang rentan terhadap gangguan menstruasi. Pada umumnya masa sekarang ini menarche terjadi pada usia rata-rata 12 tahun. Sebuah penelitian yang dilakukan oleh Fitriningtyas (2017) pada remaja putri di Pondok Pesantren Nurul Huda Kabupaten Malang Hasil penelitian menunjukkan bahwa sebagian besar reponden mengalami menarche dalam kategori usia normal (11-13 tahun) berjumlah 37 (74\%) sedangkan dalam kategori tidak normal berjumlah 13 (26\%). Sesuai dengan penelitian yang dilakukan oleh Gustina (2015) pada remaja putri di Surakarta yang menunjuk-kan bahwa responden mengalami usia menarche paling banyak yaitu pada usia 12 tahun.

Berdasarkan hasil penelitian terdahulu yang mengatakan rata-rata usia menarche remaja pada saat ini ialah 12 tahun sesuai dengan usia responden di SMA N 1 Manado yang mana usia responden yang diteliti masih termasuk dalam tahun-tahun awal menstruasi, dan tentunya hal ini dapat diambil sebagai salah satu faktor yang mempengaruhi kejadian dismenore dan gangguan siklus haid pada remaja di SMA N 1 Manado.

Remaja tahap akhir mengalami gangguan yang terkait dengan menstruasi sebesar $75 \%$, yaitu menstruasi yang tertunda, tidak teratur, nyeri, dan perdarahan yang banyak pada waktu menstruasi merupakan keluhan tersering yang menyebabkan remaja wanita menemui dokter (Sianipar dkk,2009) Hal inilah yang dapat menjadi salah satu alasan adanya hubungan antara dismenore dengan gangguan siklus haid pada remaja di SMAN 1 Manado.

Hasil dari penelitian ini yang menunjukan tingginya angka kejadian dismenore dan gangguan siklus haid pada remaja di SMA N 1 Manado, dapat berdampak pada berbagai aspek dalam kehidupan seorang remaja, contohnya dismenore dengan skala nyeri hebat dapat menghambat kegiatan aktifitas sehari-hari termasuk juga aktifitas belajar, yang juga nantinya dapat berpengaruh terhadap prestasi belajar remaja. Gangguan siklus haid yang juga dialami oleh remaja di SMA N 1 Manado dapat menimbulkan kecemasan terkait masalah kesehatan organ reproduksi, dengan berbaga asumsi yang dapat muncul, kurangnya paparan informasi mengenai kesehatan reproduksi dan seputar menstruasi juga dapat menjadi sebab dari kecemasan yang terjadi terkait dengan gangguan menstruasi yang dialami oleh remaja di SMA $\mathrm{N} 1$ Manado, mengingat hasil dari penelitian ini menunjukan bahwa tingginya angka kejadian dismenore dan gangguan siklus haid pada remaja di SMA N 1 Manado. 
ejournal Keperawatan (e-Kp) Volume 7 Nomor 1, Februari 2019

\section{SIMPULAN}

Angka kejadian dismenore pada remaja di SMA N 1 Manado sebesar $80.5 \%$, dengan keluhan terbanyak yaitu skala nyeri sedang. Gambaran siklus haid yang dialami remaja di SMA N 1 Manado sebagian besar mengalami gangguan siklus haid polimenore. Terdapat hubungan yang bermakna antara Dismenore dengan Gangguan Siklus Haid pada Remaja di SMA N 1 Manado.

\section{DAFTAR PUSTAKA}

Batubara, Jose RL. (2010). Adolescent Development (Perkembangan Remaja).

https://www.researchgate.net/publi cation/312175400_Adolescent De velopment_Perkembangan_Remaja

Felicia. (2015). Hubungan Status Gizi Dengan Siklus Menstruasi Pada Remaja Putri di PSIK FK UNSRAT.

https://ejournal.unsrat.ac.id/index.p hp/jkp/article/view/6694/6214

Fitriningtyas, dkk. (2017). Usia Menarche, Status Gizi, Dan Siklus Menstruasi Santri Putri di Pondok Pesantren Nurul Huda Malang.http://journal.um.ac.id/inde x.php/preventia/article/viewFile/10 $\underline{009 / 4752}$

Gustina, T. (2015). Hubungan antara Usia Menarche dan lama Menstruasi dengan KejadianDismenore Primer pada Remaja Putri di SMK Negeri 4

Surakarta.http://eprints.ums.ac.id/3 8652/17/NASKAH\%20PUBLIKA

SI.oke.tina.pdf

Handayani, EY. (2014). Faktor-faktor yang berhubungan dengan nyeri menstruasi (Dismenore) di Beberapa SMA di Kabupaten Rokaan Hulu. http://ejournal.upp.ac.id/index.php/akbd/a rticle/download/1107/808
Larasa, TA, Alatas, F. (2016). Dismenore Primer dan Faktor Risiko Dismenore Primer Pada Remaja.http://juke.kedokteran.unil a.ac.id/index.php/majority/article/v iewFile/1040/835

Mesarini, B.W., Astuti, V.W. (2013). Stress dan Mekanisme Koping Terhadap Gangguan Siklus Menstruasi pada Remaja Putri.http://puslit2.petra.ac.id/ejo urnal/index.php/stikes/article/vie $\underline{\mathrm{w} / 18828 / 18536}$

Milanti, dkk. (2017). Faktor - Faktor Yang Mempengaruhi Siklus Haid Pad Mahasiswa Fakultas Kedokteran Mulawarman. http://repository.unmul.ac.id/uplo ad/jurnal/file 1513205635.pdf

Pratiwi, A.Z. (2017). Hubungan Antara Usia Menarche Dengan Lama Siklus Menstruasi dan Kejadian Dismenore Primer Pada Remaja Putri di SMA N 1 Makasar. http://journal.um.ac.id/index.php/ preventia/article/viewFile/10009/ 4752

Putri, S.A. (2017). Hubungan Antara Nyeri Haid (Dismenore) Terhadap Aktivitas Belajar Pada Siswi Kelas XI SMA Negeri 52 Jakarta.

http://journal.um.ac.id/index.php/ preventia/article/download/10013 14756

Sahmin. (2017). Prevalensi Gangguan Menstruasi Pada Remaja Putri Di SMK YPKK 1 Sleman. http://repository.unjaya.ac.id/243 6/2/SAHMIN $\% 20 \% 281114118 \%$ 29.pdf

Sianipar, Olaf, dkk. (2009). Prvalensi Gangguan Menstruasi dan Faktor-Faktor Yang Berhubungan Pada Siswi SMU di Kecamatan Pulo Gadug Jakarta Timur. 
ejournal Keperawatan (e-Kp) Volume 7 Nomor 1, Februari 2019

https://www.academia.edu/23050

512/Prevalensi_Gangguan_Menst

ruasi dan Faktor-

faktor yang Berhubungan pada

Siswi_SMU di_Kecamatan_Pulo

_Gadung_Jakarta_Timur

Sinaga, dkk. (2017). Manajemen Kesehatan Menstruasi. Jakarta : Universitas Nasional.

file://C:/Users/ASUS/Documents /PROPOSAL\&SKRIPSI/referensi $\% 20 \mathrm{bab} \% 206 /$ sinaga $\% 20$ et $\% 20 \mathrm{al}$ $\% 20 B U K U-M A N A J E M E N-$ KESEHATAN-MENSTRUASIOKE.pdf

Sitoayu, L., Pertiwi, D. A., \& Mulyani, E. Y. (2017). Kecukupan Zat Gizi Makro, Status Gizi, Stres, dan Siklus Menstruasi pada Remaja. https://jurnal.ugm.ac.id/jgki/articl e/view/17867/15583 